\title{
Quality of Life among Geriatric Population: A Community-based Study in the Rural Field Practice Areas of a Tertiary Care Hospital in Mangalore
}

\author{
Narayana V*, Saurabh Kumar, Sudhir Prabhu, Sowmya Bhat, Oliver Dsouza, Nishanth Krishna, Achal Shetty, \\ Moira D'souza, Anissa Thomas, Sucharitha Suresh \\ Department of Community Medicine, Father Muller Medical College, Mangalore, Karnataka, INDIA.
}

Received: 15 August 2020;

Accepted: 30 September 2020

*Correspondence to:

Dr. Narayana $\boldsymbol{V}, M B B S, M D$ Department of Community Medicine, Father Muller Medical College, Mangalore-575002, Karnataka, INDIA.

Phone no: +91- 0824-2238000 Email:drnarayanv@gmail.com Copyright: (C) the author(s),publisher and licensee Indian Academy of Pharmacists. This is an open-access article distributed under the terms of the Creative Commons Attribution Non-Commercial License, which permits unrestricted non-commercial use, distribution, and reproduction in any medium, provided the original work is properly cited.

\begin{abstract}
Background: Quality of life among elderly needs assessment as they are the growing population nowadays and also are more vulnerable to many morbid conditions. Objectives: The objective of this study is to assess different domains of quality of life and its relationship with socio-demographic factors. Methods: A Community based study was done among 153 persons aged 60 years and above from 13.06.2018 to 20.06.2018 in the rural field practice areas of Department of Community Medicine, Father Muller Medical College, Mangalore Karnataka. The World Health Organisation, Quality of life-BREF Questionnaire was used and analysis done using SPSS version 23.0. Results: The mean Quality of life score was maximum in social health domain $(72.90 \pm 1.63)$ followed by environmental health domain $(63.10 \pm 3.71)$ and physical health domain $(61.60 \pm 2.96)$. The lowest was in psychological health domain $(57.90 \pm 2.61)$. Better scores of physical health domain, Psychological health domain and social health domain was seen among the elderly who had easy contacts with other people in the community. Environmental health domain score was better among the elderly people belonging to the Christian religion. Conclusion: In our present study, social relationship domain had higher mean Quality of life score when compared to other domains; where as psychological domain was affected badly among the elderly population. Further counselling and research can be done to explore the factors affecting the psychological domain.

Key words: Geriatric, Quality of life, Health status, India.
\end{abstract}

\section{INTRODUCTION}

Aging is a universal phenomenon accompanied by an increased risk of disease, disability, decreased functional capacity and eventually death and it affects every individual, family, community and society. ${ }^{[1]}$ The world is during a unique and irreversible process of demographic transition which will result in increasing life expectancy and increase in the proportion of elderly population in the near future.

India is the second largest population of the elderly (60 years and above) in the world after China. ${ }^{[2]}$ The percentage of persons aged 60 years and over is expected to double between 2007 and 2050 reaching to 2 billion. In India, the population of 60 years and above was $8 \%$ (8.1\% in rural India) in 2011. This is projected to increase from $8.6 \%$ in 2016 (103.9 million) to 20 \% (324 million) by 2050 a number greater than total US population in 2012. ${ }^{[3]}$ These demographic changes and the longevity revolution require medical care needs as well as special preventive health care needs of the elderly. The rising number of older Indians with changing family relationships and severely limited old age income support brings a variety of social, economic and health care policy challenges. ${ }^{[4]}$ The objective of the present study is to assess the quality of life among elderly population using WHO - QOL-BREF scale and to determine the association between socio-demographic factors and quality of life. The World Health Organization (WHO) defined QOL as "an individual's perception of life in the context of culture and value system, in which he or she lives and in relation to his or her goals, expectations, standards and concerns". Very few studies have been conducted to assess
QOL among elderly population, especially in rural areas in India, though many studies are conducted on QOL among elderly in other countries. With this backdrop, this study was done to assess different domains of QOL (Physical health, Psychological health, Social relationship and environmental health).

\section{Methods}

A community-based cross - sectional study was conducted from 13.06.2018 to 20.06.2018 for a period of 5 days. The study subjects were all the persons aged 60 years and above residing in rural communities of Bollary, Jarandagudde, Badagabellur, Ammunje and Jyothinagar, which are the rural field practice areas of Department of Community Medicine, Father Muller Medical College, Mangalore.

\section{Sample size and sampling techniques}

After using the formula for sample size calculation, the required sample size was derived to be 122 participants. Simple random sampling method was used to collect the data. However, the study was conducted on a total of 153 participants.

\section{Selection criteria}

All the residents aged 60 years and above from the selected houses were 
included in this study, while unwilling individuals, locked homes and moribund patients were excluded from the study.

\section{Study tool}

The QOL was assessed using standard questionnaire format of WHO QOL - BREF scale, this instrument contains four domains namely, Domain 1 (Physical health),

Domain 2 (Psychological health), Domain 3 (Social health) and Domain 4 (environmental health) with a total of 26 questions. Each of these domains are rated on a 5 point likert scale. As per the WHO guidelines, 25 raw scores for each domain were calculated by adding values of single items and it was then transformed to a score ranging from 0 to 100 , where 100 is the highest and 0 is the lowest value. The mean score of each domain, total score and average score was calculated. This questionnaire was translated to Kannada and then back to English for assessing the instrument.

\section{Data collection}

The study participants were interviewed at their family setting after explaining the academic nature of this research and they were assumed that information collected from them would be kept confidential. Sociodemographic characteristics, that is age, sex, education, family type, marital status and income and data on QOL were collected using a structured questionnaire.

\section{Ethical consideration}

Ethical clearance was obtained from the Institutional Ethics Committee (vide protocol number-FMMCIEC/CCM/334/2019). Informed written consent in local language was obtained from every interviewee. The female participants were interviewed in the presence of female attendants or female family members.

\section{Statistical analysis}

The collected data were entered into statistical package for the social sciences (SPSS Inc, Chicago, IL, USA) Version 23.0 and checked for any duplicate or erroneous entry. Significance of association between QOL (dependent variable) with the different independent variables was analysed by unpaired $t$ - test and $P<0.05$ was considered as statistically significant.

\section{RESULTS}

This study was conducted among 153 participants among which majority, $81(53.9 \%)$ belonged to less than 65 years age group, only $72(47.1 \%)$ were 65 years and above and $57(37.3 \%)$ were males. Most of them 99 $(64.7 \%)$ were Hindu by religion. Majority were illiterate, $50(32.7 \%)$ and by occupation unskilled workers $71(46.7 \%)$ followed by semi-skilled, $32(21.1 \%)$, unemployed, $27(17.8 \%)$, skilled i.e. $16(10.5 \%)$ and clerical i.e. $6(3.9 \%)$. As per modified B.G Prasad's classification, majority i.e. 56(36.6\%) belonged to upper lower socio-economic class. (Table 1)

Table 2 has shown the comparison of scores in all four domains of QOL with socio demographic variables. Comparing the scores obtained in the physical health domains and socio demographic characteristics, individuals $<65$ years were having better score. Hindu religion, nuclear family status and higher socioeconomic class were the factors found having better score in Psychological health domain. Comparing the scores obtained in the social relationship domains and Socio demographic variables, female participants who studied till high school and who were skilled in their occupation were having better score. In the environmental domain, the factors found to have better score were high school education, skilled occupation, higher socio-economic class.

Table 3 shows the scores for different domains of quality of life. It can be seen that the score for social relationship domain is the highest $(72.90 \%)$ and the least was for the Psychological health domain (57.90\%)

\section{DISCUSSION}

In a study done by Anjan Datta, Kaushik Nag and others, ${ }^{[3]}$ it was found that there were more females, $41(53.9 \%)$ where compared to males $35(46.1 \%)$.

In our study also there were more females, $96(62.7 \%)$ when compared to males, 57(31.3\%).

Among the females in their study social relationship domain score (60.61 \pm 10.78$)$, was more compared to other domains score. But in our study, among the females, environmental domain score (25.66 \pm 3.8$)$ was more when compared to other domain scores and was not significant. Anik Lestari and others $^{[5]}$ in their study in Indonesia found that the number of elderly less than 65 years were $107(47.7 \%)$ and $>65$ years were $117(52.3 \%)$. But in our

\begin{tabular}{|l|l|}
\hline \multicolumn{2}{|l|}{ Table 1: Distribution of the participants according to } \\
Socio demographic characteristics ( $\boldsymbol{n}=\mathbf{1 5 3})$ \\
\hline Socio demographic characteristics & Frequency, $\boldsymbol{n}$ (\%) \\
& \\
\hline Age group (years) & \\
<65 & $81(52.9)$ \\
65 and above & $72(47.1)$ \\
\hline Sex & \\
Male & $57(37.3)$ \\
Female & $96(62.7)$ \\
\hline Religion & \\
Hindu & $99(64.7)$ \\
Muslim & $52(34)$ \\
Christian & $2(1.3)$ \\
Jain & 0 \\
\hline Education & \\
Illiterate & $50(32.7)$ \\
Primary & $43(28.1)$ \\
Middle & $32(20.9)$ \\
High School & $22(14.4)$ \\
Intermediate & $6(3.9)$ \\
Graduate/PG & 0 \\
Professional/ Honours & 0 \\
\hline Occupation & \\
Unemployed & $27(17.8)$ \\
Unskilled & $71(46.7)$ \\
Semi- Skilled & $32(21.1)$ \\
Skilled & $16(10.5)$ \\
Clerical & $6(3.9)$ \\
Semi-Professional & 0 \\
Professional & 0 \\
\hline Marital Status & \\
Single & $2(1.3)$ \\
Married & $105(68.6)$ \\
Separated & 0 \\
Divorced & 0 \\
Widow/ Widower & $46(30.1)$ \\
\hline Socioeconomic class(Rs.) & \\
$<2091$ & $6(3.9)$ \\
2092-6216 & $25(16.3)$ \\
$6214-10356$ & $51(33.3)$ \\
10357-15535 & $56(36.6)$ \\
15536-20714 & $10(6.5)$ \\
20715-41429 & $5(3.3)$ \\
>41430 & $0(0)$ \\
\hline & \\
\hline
\end{tabular}




\begin{tabular}{|c|c|c|c|c|}
\hline \multirow{2}{*}{$\begin{array}{l}\text { Socio demographic } \\
\text { characteristics }\end{array}$} & \multicolumn{4}{|c|}{ Mean \pm SD } \\
\hline & $\begin{array}{l}\text { Physical } \\
\text { health } \\
\text { Domain }\end{array}$ & $\begin{array}{l}\text { Psychological } \\
\text { health Domain }\end{array}$ & $\begin{array}{l}\text { Social } \\
\text { relationship } \\
\text { Domain }\end{array}$ & $\begin{array}{l}\text { Environmenta } \\
\text { health Domain }\end{array}$ \\
\hline $\begin{array}{l}\text { Age (years) } \\
<65(n=81) \\
65 \text { and above }(n=72) \\
P \text { value }\end{array}$ & $\begin{array}{l}21.91 \pm 3 \\
21.15 \pm 2.8 \\
0.306\end{array}$ & $\begin{array}{l}17.84 \pm 2.6 \\
16.85 \pm 2.4 \\
0.420\end{array}$ & $\begin{array}{l}11 \pm 1.5 \\
10.85 \pm 1.7 \\
0.424\end{array}$ & $\begin{array}{l}25.04 \pm 3.5 \\
25.44 \pm 3.9 \\
0.169\end{array}$ \\
\hline $\begin{array}{l}\text { Sex } \\
\text { Male }(n=57) \\
\text { Female }(n=96) \\
P \text { value }\end{array}$ & $\begin{array}{l}21.49 \pm 2.8 \\
21.59 \pm 3 \\
0.956\end{array}$ & $\begin{array}{l}16.96 \pm 2.5 \\
17.61 \pm 2.6 \\
0.088\end{array}$ & $\begin{array}{l}10.77 \pm 1.6 \\
11.02 \pm 1.6 \\
0.394\end{array}$ & $\begin{array}{l}24.51 \pm 3.4 \\
25.66 \pm 3.8 \\
0.128\end{array}$ \\
\hline $\begin{array}{l}\text { Religion } \\
\text { Hindu }(n=99) \\
\text { Christian }(n=2) \\
\text { Muslim }(n=52) \\
P \text { value }\end{array}$ & $\begin{array}{l}21.64 \pm 3 \\
22 \pm 2.8 \\
21.38 \pm 2.7 \\
0.990\end{array}$ & $\begin{array}{l}17.48 \pm 2.6 \\
16 \pm 4.2 \\
17.21 \pm 2.4 \\
0.806\end{array}$ & $\begin{array}{l}10.69 \pm 1.8 \\
12.50 \pm 0.7 \\
11.33 \pm 1.1 \\
0.109\end{array}$ & $\begin{array}{l}25.28 \pm 3.7 \\
30 \pm 4.2 \\
24.94 \pm 3.5 \\
0.606\end{array}$ \\
\hline $\begin{array}{l}\text { Education } \\
\text { Illiterate }(n=50) \\
\text { Primary }(n=43) \\
\text { Middle }(n=32) \\
\text { High School }(n=22) \\
\text { Intermediate }(n=6) \\
P \text { value }\end{array}$ & $\begin{array}{l}21.14 \pm 3.2 \\
21.72 \pm 2.8 \\
21.94 \pm 2.8 \\
22.09 \pm 2.7 \\
19.83 \pm 2.1 \\
0.271\end{array}$ & $\begin{array}{l}17.08 \pm 3.1 \\
17.40 \pm 2.1 \\
17.56 \pm 2.5 \\
17.64 \pm 2.2 \\
17.67 \pm 3 \\
0.658\end{array}$ & $\begin{array}{l}10.64 \pm 1.9 \\
10.77 \pm 1.3 \\
11.16 \pm 1.5 \\
11.50 \pm 1.3 \\
11.17 \pm 0.7 \\
0.940\end{array}$ & $\begin{array}{l}25.06 \pm 3.9 \\
24.74 \pm 3.5 \\
25.06 \pm 3.8 \\
26.68 \pm 3.5 \\
25.67 \pm 1.7 \\
0.887\end{array}$ \\
\hline $\begin{array}{l}\text { Occupation } \\
\text { Unemployed }(n=27) \\
\text { Unskilled }(n=71) \\
\text { SemiSkilled }(n=32) \\
\text { Skilled }(n=16) \\
\text { Clerical }(n=6) \\
P \text { value }\end{array}$ & $\begin{array}{l}20.56 \pm 3.2 \\
21.99 \pm 2.7 \\
20.88 \pm 2.6 \\
22.94 \pm 3.7 \\
21.50 \pm 1.3 \\
0.573\end{array}$ & $\begin{array}{l}16.63 \pm 3.3 \\
17.61 \pm 2.2 \\
16.97 \pm 2.6 \\
18.19 \pm 2.8 \\
17.50 \pm 2 \\
0.297\end{array}$ & $\begin{array}{l}10.37 \pm 1.9 \\
10.94 \pm 1.6 \\
11.03 \pm 1.3 \\
11.38 \pm 1.7 \\
11.33 \pm 1.5 \\
0.825\end{array}$ & $\begin{array}{l}24.33 \pm 37.7 \\
24.62 \pm 3.9 \\
26.03 \pm 3.1 \\
27.25 \pm 3.4 \\
26.50 \pm 2.9 \\
0.388\end{array}$ \\
\hline $\begin{array}{l}\text { Marital Status } \\
\text { Single }(n=2) \\
\text { Married }(n=105) \\
\text { Widow/ Widower }(n=46) \\
P \text { value }\end{array}$ & $\begin{array}{l}19 \pm 2.8 \\
21.55 \pm 2.8 \\
21.67 \pm 3.2 \\
0.322\end{array}$ & $\begin{array}{l}16.50 \pm 2.1 \\
17.55 \pm 2.5 \\
17 \pm 2.8 \\
0.982\end{array}$ & $\begin{array}{l}9.50 \pm 0.7 \\
11 \pm 1.5 \\
10.83 \pm 1.8 \\
0.688\end{array}$ & $\begin{array}{l}22.50 \pm 0.7 \\
25.12 \pm 3.5 \\
25.29 \pm 4.2 \\
0.130\end{array}$ \\
\hline $\begin{array}{l}\text { Type of family } \\
\text { Nuclear }(n=90) \\
\text { Joint }(n=63) \\
\text { P value }\end{array}$ & $\begin{array}{l}21.67 \pm 2.9 \\
21.40 \pm 2.9 \\
0.790\end{array}$ & $\begin{array}{l}17.47 \pm 2.6 \\
17.24 \pm 2.5 \\
0.985\end{array}$ & $\begin{array}{l}11.04 \pm 1.6 \\
10.76 \pm 1.6 \\
0.311\end{array}$ & $\begin{array}{l}25.30 \pm 3.4 \\
25.13 \pm 4.1 \\
0.705\end{array}$ \\
\hline $\begin{array}{l}\text { Socioeconomic } \\
\text { class(PCI) (Rs.) } \\
<2091(n=6) \\
2092-6216(n=25) \\
6214-10356(n=51) \\
10357-15535(n=56) \\
15536-20714(n=10) \\
20715-41429(n=5) \\
P \text { value }\end{array}$ & $\begin{array}{l}19.50 \pm 2.5 \\
21.48 \pm 3.4 \\
21.55 \pm 2.6 \\
21.70 \pm 3.1 \\
22 \pm 2.7 \\
22 \pm 1.5 \\
0.942\end{array}$ & $\begin{array}{l}16.67 \pm 3.9 \\
17.64 \pm 2.8 \\
17.29 \pm 2.2 \\
17.29 \pm 2.8 \\
18 \pm 2 \\
17.40 \pm 2.5 \\
0.211\end{array}$ & $\begin{array}{l}9.33 \pm 2 \\
10.40 \pm 2.4 \\
11.33 \pm 1 \\
10.86 \pm 1.4 \\
11.20 \pm 1.6 \\
11.60 \pm 1.5 \\
0.969\end{array}$ & $\begin{array}{l}22.67 \pm 4 \\
24.28 \pm 4.6 \\
24.94 \pm 3.2 \\
25.41 \pm 3.4 \\
27.30 \pm 2.8 \\
29.80 \pm 2.3 \\
0.971\end{array}$ \\
\hline
\end{tabular}

study, $<65$ years were $81(52.9 \%)$ and $>65$ years were $72(47.1 \%)$.

These findings are contradictory as there are more number of elderly $<65$ in our study and there are less number of elderly in $<65$ years age group in their study. Also the $>65$ year age group shows more number of elderly in their study and less in our study. In our study we found that the QOL was good for both $<65$ years age group and $>65$ years group in the environment health domain which was not statistically significant. In a study done by Nabarun Karmakar and others (4) among the different religions, there were more Hindus, $62(81.5 \%)$ than others. This was similar to our study where in there were more of Hindus, $99(64.7 \%)$ compared to other religions.

It was seen in this study that among the Hindus, QOL was better in the social relationship domain (66.68 \pm 14.91$)$. But in our study among the Hindus better QOL was seen in environmental health domain (25.28 \pm 3.7$)$ and in both studies were statistically not significant.

In another study conducted by Bharti Chawla $e t$ al. ${ }^{[6]}$ it was found that there were more illiterates, $57(57 \%)$ among the elderly group. This is similar to our study as there were more illiterates $50(32.7 \%)$ when the level of education was considered.

This study revealed that environmental health domain score $(62.23 \pm 10.54)$ was more compared to other QOL scores. This was statistically not significant. In our study also among the illiterates, environmental domain score $(250.6 \pm 3.9)$ was more among other domain scores, which is not statistically significant. A study done by Ayman Mohammed Elsous and others ${ }^{[7]}$ showed that the elderly earned their income through social support, $71(35.3 \%)$. In our study the elderly mainly earned their livelihood by unskilled labour, $71(46.7 \%)$. The QOL in our study was better in the environmental 


\begin{tabular}{|l|c|l|l|l|l|}
\hline \multicolumn{6}{|l|}{ Table 3: Scores for different domains of quality of life. } \\
\hline $\begin{array}{l}\text { Domains of } \\
\text { QOL }\end{array}$ & $\mathbf{( n )}$ & $\begin{array}{l}\text { Maximum } \\
\text { score }\end{array}$ & Mean & $\begin{array}{l}\text { Std. } \\
\text { Deviation }\end{array}$ & $\begin{array}{l}\text { Mean } \\
\%\end{array}$ \\
\hline Physical & 153 & 35 & 21.56 & 2.96 & 61.60 \\
\hline Psychological & 153 & 30 & 17.37 & 2.61 & 57.90 \\
\hline Social & 153 & 15 & 10.93 & 1.63 & 72.90 \\
\hline Environmental & 153 & 40 & 25.23 & 3.71 & 63.10 \\
\hline Total QOL & 153 & 120 & 75.08 & 8.71 & 62.60 \\
\hline
\end{tabular}

health domain (24.62 \pm 3.9$)$ for the unskilled labourer which was statistically not significant.

Oladipupo et al..$^{[8]}$ in Nigeria conducted a study on elderly and it showed that there were more number of unmarried elderly $126(100 \%)$ than the married $90(100 \%)$ in the study group. This was different from our study as there was more number of married people, 105 (68.6\%) than the unmarried. When the QOL among the married and unmarried was considered, the married people enjoyed a better QOL than the unmarried (31.1\% Vs $20.6 \%)$. This was not statistically significant. Among the married elderly in our study, environmental health domain score (25.12 \pm 3.5$)$ was better than other domain scores. This was statistically not significant.

Anjan Datta and others (3) found that among the elderly studied, there were more number of nuclear families $(56.6 \%)$ than the joint families, $33(43.4 \%)$. This is similar to our study where there was also more number of nuclear families, $90(58.8 \%)$ than the Joint families, 63(41.2\%) When the domain scores were observed in their study, social relationship domain score $(59.72 \pm 12.78)$ was better than other scores and not statistically significant.

In our study it was different and the environmental domain score (25.30 \pm 3.4$)$ was more than other domains scores, where the QOL was considered. These were also statistically not significant. When the socio-economic status of the elderly was studied, Nabarun Karmakar and others did a study and in that it was seen that majority of the elderly belonged to the upper lower SES scale, $33(43.4 \%)$. Our study also showed that the QOL was good in the upper middle SES scale, 56(36.6\%). This shows that the elderly who were financially better enjoyed a good QOL. This was not statistically significant. For the SES in this study, it was found that social relationship domain score was better $(25.41 \pm 3.4)$ than other domain scores. It was also not statistically significant.

Mohammed Tanveer Ahmed \& others ${ }^{[9]}$ did a study on quality of life among the elderly in Bangalore city. In this study it was seen that, when the scores for different domains of quality of life was considered, social relationship domain score, $(59.23 \pm 12.27)$ had a better score, but the environmental health domain score $(44.55 \pm 12.54)$ was poor. This is because the elderly had established good social network, but had poor environmental factors in the slum areas where they were living. But in our study, also, social health domain $(72.90 \%)$ was better compared to other domains. Psychological health domain $(52.90$ $\%$ ) was poor among all domains. This shows that although the elderly had good social relationship in the society they suffered from many psychological problems like mental worries, loss of memory, loneliness and depression.

\section{CONCLUSION}

In our present study social relationship domain score was better while the Psychological domain score was poor. Overall quality of life of the elderly was poor and they were very often staying at the old age homes. This shows that the elderly was not treated well by their family members, in their own homes and hence they were forced to stay in the old age homes. Further counselling and qualitative research can be done to explore the factors affecting the psychological health domain.

\section{ACKNOWLEDGEMENT}

We acknowledge the families who participated in this study in the rural field practice areas of our department without whom this study would not have been conducted.

\section{CONFLICT OF INTEREST}

The authors declare that there is no conflict of interest.

\section{REFERENCES}

1. Nabarun K, Anjan D, Kaushik N, Kaushik T. Tripura Quality of life among geriatricpopulation: A cross - sectional study in a rural area of Sepahajila District, Tripura. Indian J Public Health. 2018;62(2):95-9.

2. Shiv P, Saurav K. Perceived stress and quality of life of elderly living separately from their adult children: A cross sectional comparative study. International Journal of Health Sciences and Research. 2019;9(4):7-13.

3. Anjan D, Kaushik N, Nabarun K, Kasuhik T. Quality of life among population in an urban area of Tripura, India. J Clin Diag Res. 2018;12(4):8-12.

4. Vishweswara RG, et al. Quality of Life among elderly population in an urban slum of Tirupathi city. Int J Community Med Public Health. 2019;6(6):2430-4.

5. Anik L, Bhisma M, Sapja A, Diffah H. Social Determinants of health related to the quality of life among the elderly in developing country (study in central Java, Indonesia). Innovare Journal of Health Sciences. 2019;7(1):1-4.

6. Bharti C, et al. Take a stand against ageism: Quality of life among elderly in a rural area of Himachal Pradesh. Indian J Community Med Public Health. 2018;8(5):3582-7.

7. Ayman ME, Mohmoud MR, Ezat AA, Ayman M, Abu M. Quality of Life amongelderly residents in the Gaza strip: A community based study. Annals of Saudi Medicine. 2019;39(1):1-7.

8. Oladipupo OF, et al. Determinants of quality of life of elderly patients attending a general practice clinic in Southwest Nigeria. Int Quart Community Health Edu. 2018;39(1):3-7.

9. Ahmed MT, Jadhav J, Sobagaiah RT, Vishwanatha. Assessment of quality of life and activities of daily living among geriatric population in Bangalore city. Int $\mathrm{J}$ Community Med Public Health. 2017;4(10):3842-5. 